\title{
DOM QUIXOTE E O GAÚCHO CAMPEIRO: UMA LEITURA FENOMENOLÓGICA NA MEDIAÇÃO DA REALIDADE
}

\author{
Don Quixote and the pampas gaucho: a phenomenological reading in mediation \\ of reality
}
Don Quijote y el gaucho campero: una lectura fenomenológica en la mediación de la realidad

Marcela Guimarães Silva

Professora na Universidade Federal do Pampa marcelasilva@unipampa.edu.br

Tiago Costa Martins

Professor na Universidade Federal do Pampa tiagomartins@unipampa.edu.br

\section{Resumo}

A partir de um exercício metodológico de tipo-ideal este artigo tem por objetivo compreender a dinâmica das múltiplas realidades que envolvem o mundo social, especialmente o mundo dos gaúchos campeiros oriundos do interior do Rio Grande do Sul, Brasil. A compreensão da fenomenologia social, através do ensaio de Alfred Schutz sobre a obra de Miguel de Cervantes, Dom Quixote, é a base comparativa para entender como o contexto social, as interações em co-presença e as interações mediadas são elementos que compõe o processo de construção da realidade. O estudo empírico realizado com os gaúchos do meio rural, especialistas nas atividades pastoris, destaca uma realidade particular e positiva para o entendimento do território, do desenvolvimento e da condição de vida. Os resultados sob o ponto de vista fenomenológico são pertinentes ao se analisar o contexto social e as interações estabelecidas no "âmbito de significado finito" na vida desses agentes sociais.

Palavras-chave: Cultura. Interação. TICs.

\begin{abstract}
From a methodological exercise of ' ideal-type', this article aims to understand the dynamics of multiple realities which involve the social world, specially the world of pampas gauchos coming from the interior of Rio Grande do Sul, Brazil. The comprehension of the social phenomenology, through the essay by Alfred Schutz on the work of Miguel de Cervantes, Don Quixote, is the comparative basis to understand how the social context, the co-presence interactions and the mediated interactions are elements that compose the process of reality construction. The empirical study done with gauchos from rural area, experts in pastoral activities, highlights a particular and positive reality to the understanding of the territory, development and life condition. The results under the phenomenological view are relevant
\end{abstract}


when analyzing the social context and the interactions established in the "range of finite meaning" in the lives of these social agents.

Keywords: Culture. Interaction. TICs.

\section{Resumen}

A partir de un ejercicio metodológico del tipo-ideal el articulo tiene por objetivo comprender la dinámica de las múltiples realidades que involucran el mundo social, especialmente el mundo de los gauchos camperos oriundos del interior de Rio Grande do Sul, Brasil. La comprensión de la fenomenología social a través del ensayo de Alfred Schutz sobre la obra de Miguel de Cervantes, Don Quijote, es la base comparativa para entender cómo el contexto social, las interacciones en copresencia y las interacciones mediadas son elementos que componen el proceso de construcción de la realidad. El estudio empírico realizado con los gauchos del medio rural, especialistas en las actividades pastoriles, destaca una realidad particular y positiva para entendimiento del territorio, del desenvolvimiento y de la condición de vida. Bajo un punto de vista fenomenológico los resultados son pertinentes y, al analizar el contexto social y las interacciones establecidas en él, "ámbito de significado finito" en la vida de esos agentes sociales.

Palabras-clave: Cultura. Interacción. TICs.

\section{INTRODUÇÃO}

Em sua grande maioria as percepções de quem efetua a leitura de "Dom Quixote de la Mancha” de Miguel de Cervantes é a de que está se tratando de um caso de loucura em plena Espanha do século XVIII. A priori não é possível conceber como uma pessoa normal, aquela que vê um moinho como um dragão; considera uma estalagem como um castelo; ou faz de uma bacia de barbeiro o seu elmo.

No entanto, Alfred Schutz (1983) em um contundente artigo intitulado "Dom Quixote e o problema da realidade" desvela uma importante consideração na novela de Cervantes: as aventuras do cavaleiro andante são variações cuidadosamente elaboradas para compreender de que forma experimentamos a realidade. Para Schutz, Dom Quixote expõe o problema das múltiplas realidades. O mundo da cavalaria é analisado como uma província finita de significados, com a sua quantidade de conhecimento próprio, forma de relacionamento com a realidade, dispositivos de controle social e as suas percepções sobre o tempo e o espaço. Diferenciando-se assim da vida cotidiana enraizada à luz do senso comum (CORREIA, 2002).

Por trás das aventuras quixotescas está toda a base conceitual e reflexiva da fenomenologia social de Schutz. Corrente sociológica que contribui decisivamente para 
“conciliar o rigor científico e o respeito a subjetividade humana presente e atuante na estrutura da realidade." (CAPALBO, 1979, p.07).

Mas que conexões são possíveis realizar com um segmento social, intitulado gaúcho campeiro? Há aproximações de "loucura" deste segmento social com Dom Quixote? Onde se insere a comunicação para Dom Quixote e para o gaúcho campeiro? Tais questões ficam mais expressivas ao se contextualizar a vida desses indivíduos. A região da Campanha do Rio Grande do Sul é considerada de parco dinamismo econômico e com uma série de indicadores que do senso comum ao estrito indicam esse território como não desenvolvido.

No entanto, ao desenvolver uma pesquisa com esse segmento social, Martins (2011) revela uma concepção de desenvolvimento condizente com a situação de vida e a ordem econômica do território. A questão chave, então, passa a ser como esses indivíduos articulam sua ideia de desenvolvimento e a compreensão de viverem num espaço desenvolvido.

Assim, a partir dos preceitos da fenomenologia de Alfred Schutz e utilizando-se de estudos e pensamentos auxiliares buscar-se-á compreender o processo de construção da realidade dos gaúchos campeiros partindo do ensaio apresentado por Schutz (1983). A associação entre o personagem de Miguel de Cervantes e o gaúcho campeiro não deixa de ser um exercício reflexivo baseado em um tipo-ideal.

\section{DOM QUIXOTE E AS EXPERIÊNCIAS DA REALIDADE}

A fenomenologia é entendida como uma perspectiva sociológica inserida no interacionismo simbólico. O interacionismo, de modo geral, concentra-se na interação no nível micro e na forma em que os significados são elaborados e transformados entre os integrantes da sociedade (GIDDENS, 2012). Por seu turno, a fenomenologia salienta a maneira como a vida social é vivenciada na realidade. "Fenomenologia é o estudo sistemático de fenômenos; das coisas como aparecem em nossa experiência” (GIDDENS, 2012, p. 73).

O debate apresentado pela fenomenologia de Schutz (CAPALBO, 1979) transita pela objetividade, para estudar grupos, instituições, e relações sociais, e pela subjetividade em que estuda os atos e a personalidade social. Em especial, ele defende o método subjetivo inspirado na sociologia compreensiva de Max Weber.

Se na associação científica ele já demonstra não estar voltado para o rigor científico da objetividade, na compreensão do mundo social, base da sua teoria, Schutz será enfático na 
importância da subjetividade. Para ele, toda a diferença entre real e irreal se baseia em dois fatos mentais: cada indivíduo é propício a pensar de modo distinto sobre o mesmo objeto; e quando isso se realiza, pode-se optar por qual modo de pensar se adere ou se ignora. "A origem e a fonte de toda a realidade, seja de um ponto de vista absoluto, seja prático, sempre está em nós mesmos.” (SCHUTZ, 1983, p. 191).

Como corolário é possível inferir uma infinidade de diferentes ordens de realidade. Melhor dito, "os agentes percebem o mundo, não como uma ou duas, mas como uma multiplicidade de realidades" (CORREIA, 2002, p. 57). Nesse aspecto, usando do pensamento de William James, menciona que essas realidades possuem estilos peculiares de existência e são separadas das demais, assim denomina-as de subuniversos. Por exemplo, pode-se dizer que há o "mundo dos sentidos" ou das "coisas físicas", voltados para o senso comum; o "mundo da ciência"; os "mundos sobrenaturais"; e os mundos da pura ociosidade e loucura. Segundo Schutz (1983) todo o objeto que se pense está em pelo menos a um dos mundos destes exemplos. "Cada um desses mundos, enquanto desperta nossa atenção, é real a seu próprio modo, e qualquer que seja a sua relação com nossa mente, se não houver uma relação mais forte com a qual se conflitue, bastará para tornar este objeto real" (SCHUTZ, 1983, p. 192).

A forma como se experimenta a realidade está, sim, na forma como a experimentamos. Objetividade e subjetividade estão dialeticamente interligadas. E mais, a própria subjetividade está, em si, interligada com outras subjetividades. Nesse contexto está presente o mundo intersubjetivo. Segundo Capalbo (1979), o homem que vive sua atitude natural, sua vida cotidiana está ciente que existem outros homens que são dotados de inteligência, sentimentos e que são passíveis de conhecer e agir. Assim, as coisas são conhecidas por ele e pelos outros homens.

Mas o homem na atitude natural percebe, também, que o mesmo objeto de seu conhecimento pode aparecer um pouco diferente para o outro se a sua posição ou a sua situação no mundo for um pouco diferente da sua. É a descoberta da perspectiva no mundo social. Nela o corpo se percebe como o centro de sua orientação na ordem espaço-temporal do mundo. Estas perspectivas, um pouco diferentes umas das outras, indicam que eu vejo melhor certos aspectos das coisas, enquanto que outros podem permanecer desaparecidos para mim. Assim, o mundo me aparece sob certo prisma, sob certa ótica, sob uma perspectiva determinada, e eu o organizo num sistema de coordenadas cujo centro sou eu. (CAPALBO, 1979, p. 54). 
A intersubjetividade se apresenta como o intercâmbio e a troca de perspectivas. Isso pressupõe a articulação das coordenadas do 'aqui' (onde eu estou) e do 'lá'(onde o meu semelhante está). Ou seja, as possibilidades de que na troca de posição "eu apreenda os mesmos aspectos que ele apreende agora e que eu adote o mesmo sistema de coordenadas" (CAPALBO, 1979, p. 55) são vistas como a idealização do intercâmbio de pontos de vista.

Ademais, nota-se ainda a noção intrínseca de situação. Situação para Schutz está em relação explícita com a vida e a história pessoal de cada um dos membros do mundo social, o contexto de vida inserido no passado e no presente de cada indivíduo. Ou seja, tal como menciona Capalbo (1979, p. 55) "cada um de nós ocupa um lugar determinado na sociedade, cada um de nós desempenha um papel, possui um status, tem certas posições intelectuais, políticas, éticas e religiosas".

Desta forma, a análise da obra "Dom Quixote de la Mancha" se reveste de uma compreensão fenomenológica esclarecedora. É oportuno contextualizar a aventura novelesca do espanhol Miguel de Cervantes para, assim, compreender o mundo da vida dos gaúchos campeiros.

Dom Quixote é uma produção bibliográfica datada de 1605. À época, os chamados romances de cavalaria possuíam grande sucesso entre a população da Espanha. A obra em si é uma sátira a esse contexto. O personagem principal da narrativa, o senhor Alonso Quijana, é de origem e convívio rural, envolto pelas leituras de histórias de cavalaria contidas nos livros de romance, vê-se tomado pela fantasia, e autodenomina-se cavaleiro e 'Dom', 'Dom Quixote'. As inserções sociológicas presentes na leitura da obra remetem ao transtorno de viver o real e o irreal. Pode-se dizer que é esta a temática abordada no decorrer da história do fidalgo Dom Quixote e de seu fiel escudeiro Sancho Pança.

Para este estudo, o primeiro ponto de destaque, que, diga-se de passagem, não foi explorado por Schutz no ensaio sobre Dom Quixote, diz respeito ao contexto de vida de Alonso Quijana. O personagem vive numa área rural. Mora em sua propriedade rural e "tinha em casa uma ama que passava dos quarenta, uma sobrinha que não chegava aos vinte, e um moço da posada e de porta afora, tanto para o trato do rocim, como para a fazenda" (CERVANTES, 1978, p. 29).

Inicialmente pode-se dizer que tanto Alonso quanto sua personificação em Dom Quixote estavam num contexto voltado para o meio rural: Alonso antes dos "devaneios" era um homem do lugar, cuidava dos afazeres na fazenda; Dom Quixote ao se tornar cavaleiro 
andante percorria grandes distâncias para chegar em alguma vila, casa, "castelos". Andava no campo ou em estradas sempre em busca de aventuras. Certas vezes, entre uma aventura e outra, conseguia abrigo em estalagens e galpões. Por fim, se relacionava com personagens, tais como: ferreiro; cavaleiros do trabalho rural; pastores de ovelhas; dentre outros. Espaço e pessoas que pertenciam, ou poderiam pertencer, aos dois subuniversos.

Ou seja, a experiência no mundo social foi construída pelo personagem através de experiências diretas. Como sugerem Berger e Luckmann (1996, p. 40) "a realidade da vida cotidiana apresenta-se como um mundo intersubjetivo, um mundo de que participo juntamente com outros homens. Esta intersubjetividade diferencia nitidamente a vida cotidiana de outras realidades das quais tenho consciência”. Nas ideias de Schutz quando há comunidade de espaço e tempo a situação face a face se efetiva. Isso, em grande medida, acontecia na vida de Alonso Quijana.

No entanto, o que chama a atenção de Schutz (1983) e que o faz construir o argumento da realidade em Dom Quixote é o mundo da cavalaria criado pelo personagem. Como Dom Quixote configura essa realidade? Em grande medida pela imersão nas leituras de livros da cavalaria. Já no primeiro capítulo das aventuras fica claro que os livros influenciaram a construção da realidade de Quixote.

É pois de saber que este fidalgo, nos intervalos que tinha de ócio (que eram os mais do ano), se dava a ler livros de cavalarias, com tanta afeição e gosto, que se esqueceu quase de todo do exercício da caça, e até da administração do seus bens; e a tanto chegou a sua curiosidade e desatino neste ponto, que vendeu muitos trechos de terra de semeadura para comprar livros de cavalarias que ler, com o que juntou em casa quantos pôde apanhar daquele gênero. (CERVANTES, 1978, p. 29).

A imersão no 'mundo' dos encantamentos, batalhas, amores, tormentas, desafios o coloca em experiência indireta no mundo social, aquele mundo da cavalaria. $\mathrm{O}$ 'problema' de Quijana é identificado pela sobrinha, padre e barbeiro como oriundo dos livros. Tanto que em um episódio os dois últimos resolvem queimar vários livros e fechar a porta da biblioteca de Quijana para não mais alimentar a ideia de que seria ele Dom Quixote. No episódio, ao mencionar o livro Amadis de Gaula o padre diz:

- Parece coisa de mistérios esta porque, segundo tenho ouvido dizer, este livro foi o primeiro de cavalarias que em Espanha se imprimiu, e dele procederam todos os demais; por isso entendo que, por dogmatizador de tão má seita, sem remissão o devemos condenar ao fogo. 
- Não senhor - disse o barbeiro; - também eu tenho ouvido dizer que é o melhor de quantos livros neste gênero se têm composto; e por isso, por ser único em sua arte, se lhe deve perdoar.

- Verdade é - disse o cura; - por essa razão deixemo-lo viver por enquanto. Vejamos esse outro que está ao pé dele. (CERVANTES, 1978, p. 46).

Na sequência da narrativa os personagens citam inúmeras obras de cavalaria. Livros impressos no século XVI na Espanha: Valência, 1521; Sevilha, 1533; Valladolid, 1556; Barcelona, 1564; dentre outros. A obra de Cervantes parece retratar um movimento da época, fora da ficção quixotesca. A censura do 'mundo real' também atingiu os livros da cavalaria. $\mathrm{O}$ padre jesuíta italiano Antonio Possevino (1534 - 1611), por exemplo, "atacou os romances de cavalaria como 'estratagemas de Satã' (talvez por darem ênfase ao amor e à magia)" (BRIGGS \& BURKE, 2006, p. 57).

Segundo Thompson (1998, p. 60), “à medida que a leitura dos livros impressos foi se propagando ao longo do século XVI, uma grande quantidade de livros foi sendo impressa nas línguas vernáculas, em vez do latim”. Assim, para além do que a aventura apresenta, e o que se pode conferir como 'subuniverso real', está o início de outra forma de experienciar a realidade: a interação mediada. Se outrora a interação face a face acontecia num contexto de copresença no espaço e no tempo, essa nova forma de interação se desloca do ambiente físico, não sendo mais necessária a partilha do ambiente espaço-temporal.

[...] O desenvolvimento dos meios de comunicação cria novas formas de ação e de interação e novos tipos de relacionamentos sociais - formas que são bastante diferentes das que tinham prevalecido durante a maior parte da história humana. Ele faz surgir uma complexa reorganização de padrões de interação humana através do espaço e do tempo. (THOMPSON, 1998, p. 77).

Desta forma, a presença dos livros na situação de vida de Dom Quixote (re)configura os padrões de interação e amplia sua possibilidade de construir seu mundo social, ou mesmo de participar de diferentes subuniversos, como se poderia chamar a cavalaria. Schutz vai propor que essa forma de apreender a realidade está contida dentro de um esquema de tipificação na qual a realidade social está totalmente anônima e transcendente para o agente social. Ele define como "região das realidades sociais transcendentes" aquelas "tipificações relativas aos objetos culturais, aos sistemas de signos e aos produtos da fabricação industrial [...]." (CAPALBO, 1979, p. 71). Assim, para Dom Quixote a rotina de ler inúmeros livros de cavalaria ocasionaria que "quanto mais regular, habitual, padronizado for o esquema, tanto maior serão as chances de que os parceiros se entendam.” (CAPALBO, 1979, p. 72). 
Desta forma, Schutz (1983, p. 193) questiona como "conseguimos manter nossa crença na realidade do subuniverso fechado que escolhemos uma vez como nossa base doméstica, apesar de inúmeras irrupções de experiências que o transcendem”. Eis o problema da realidade em Dom Quixote.

\section{DOM QUIXOTE E O PROBLEMA DA REALIDADE}

O mundo da cavalaria é o subuniverso de Dom Quixote e é sobre este que ele confere o valor da realidade. Ele refuta as dúvidas sobre esse mundo, as vidas e aventuras descritas nos livros com bons argumentos (SCHUTZ, 1983). Primeiramente, sugere que a instituição dos cavaleiros é universalmente reconhecida. Menciona a história do Rei Artur na Inglaterra; o detalhe da vida, família e a época dos cavaleiros no seu dia a dia; a descoberta de maxilares e clavículas que comprovavam a existência de gigantes; e a permissão da realeza em imprimir tais livros. Assim, como sugere Schutz (1983, p. 193):

Se examinarmos por que, dentro da realidade de nossa atitude natural, acreditamos em fatos históricos, só poderemos pensar em argumentos semelhantes aos de Dom Quixote: documentos, monumentos, relatos autenticados por testemunhas e pela tradição contínua.

Por outro lado, o subuniverso de Dom Quixote se destaca por modificações singulares de categorias de pensamento. Tempo e espaço e, mais particularmente, causalidade. Este último é significativo através da presença dos encantadores existentes no decorrer das aventuras do fidalgo. Em algumas circunstâncias a suposição da existência de um mágico capaz de transformar algumas coisas em ações amigáveis ou hostis, preenche o papel de causalidade e motivação no subuniverso de Dom Quixote (SCHUTZ, 1983).

Sua atividade é a categoria básica da interpretação do mundo do cavaleiro. Sua função é traduzir a ordem do reino da fantasia nos reinos da experiência do senso comum, transformar os gigantes reais atacados por Dom Quixote em fantasmas de moinhos de vento, por exemplo. Os encantadores, segundo aprendemos, podem transformar todas as coisas e mudar suas formas naturais. Mas, estritamente falando, o que eles mudam é o esquema de interpretação que prevalece em um subuniverso no esquema de interpretação válido em outro. (SCHUTZ, 1983, p. 195).

A existência dos encantadores é um fato histórico provado pelos livros de cavalaria não verificável pelos meios comuns de percepção sensorial. Os mágicos não são vistos e "é claro que o axioma do encantamento, que reconcilia o subuniverso da fantasia e o da realidade 
preponderante possível, não pode ser ele mesmo submetido a um teste originado dentro de um desses subuniversos" (SCHUTZ, 1983, p. 195).

É assim que, para encarar essas diferenças entre mundos, Dom Quixote e os demais tiveram de enfrentar os conflitos de interpretação, oriundos dos esquemas díspares, que prevaleceram em cada uma das situações. Está em voga aqui a noção fenomenológica de Schutz ao "âmbito de significado finito".

Schutz aprofundou de modo particularmente hábil o conceito de âmbito de significado finito como as numerosas realidades que constituem o mundo da vida e que são olhadas como reais enquanto se dirige para elas a atenção da consciência: a embriaguez, o sonho, a loucura, o êxtase religioso ou a experiência estética (CORREIA, 2002, p. 10).

As aventuras do cavaleiro andante são elucidativas e, nesse sentido, torna-se oportuno citar dois exemplos. Na sua primeira aventura fica bem destacado o contexto de vida de Quijana: uma estalagem; um porqueiro tocando o chifre; duas mulheres de vida fácil; e um estalajadeiro. Já para Dom Quixote o que se vê é uma fortaleza com torres de prata, uma trombeta de anão anunciando o cavaleiro, formosas donzelas e um castelão.

O que ocorre na aventura é que nada e ninguém contradizem o que Dom Quixote vive de realidade. Como aponta Schutz, o estalajadeiro, ou castelão, recebe-o de forma condizente a um cavaleiro, permite a observação dos brasões e arma-o cavaleiro. Os vendedores de seda e o muleiro se comportam de forma compatível com a interpretação de mundo da cavalaria. “Assim, as ações de Dom Quixote permanecem plausíveis dentro da realidade preponderante da vida cotidiana, apesar de suas motivações fantásticas, e nenhum encantador é necessário para reconciliar os esquemas díspares de interpretação." (SCHUTZ, 1983, p. 197).

No segundo exemplo do fenomenólogo tem-se a aventura da conquista do elmo de Dom Quixote. Vendo ao longe um homem num cavalo, Dom Quixote visualiza o capacete da armadura do cavaleiro brilhando. O que para o fidalgo era um conjunto formado por cavalo, cavaleiro e elmo, para o fiel escudeiro Sancho Pança, empírico neopositivista (SCHUTZ, 1983), era um homem escarranchado num asno pardo que levava na cabeça uma coisa que reluz: uma bacia. $\mathrm{O}$ barbeiro regressava de dois afazeres profissionais e trazia consigo a sua bacia de latão. "Como no caminho lhe começou a chover, receoso ele de que lhe estragasse o chapéu, (...), pôs-lhe por cima a bacia, que, por estar areada de pouco tempo, resplandecia a meia légua de distância." (CERVANTES, 1978, p. 115). 
Dom Quixote investe sobre o barbeiro na tentativa de combater com o "cavaleiro" para conquistar o elmo. Facilmente se faz vencedor da aventura e tão logo coloca a bacia, para ele um elmo, sobre a cabeça. O fidalgo e Sancho passam a dialogar constantemente sobre a definição "real" do objeto. Sancho descobre que se quiser estabelecer um universo de discurso com Dom Quixote precisará aceitar o esquema de interpretação do cavaleiro

Por diversas vezes, Sancho corrige sua afirmação inicial de que o que Dom Quixote declara como, sendo o escudo de Mambrino não passa de uma bacia de barbeiro, e que vale tanto quanto um tostão se valer um real. Nada se parece mais com uma bacia de barbeiro. É exatamente igual. E, depois, chega a falar numa "bacia-escudo". Mais para o final da primeira parte, a estória desta aventura é utilizada para desenvolver, como na parte acelerada de uma fuga complicada, o tema principal da realidade intersubjetiva em novas elaborações. (SCHUTZ, 1983, p. 199).

No decorrer da aventura essa ideia se amplia ao grupo. Na estalagem, com tom de brincadeira, todos os atores principais da aventura se reúnem e confirmam a ideia de Dom Quixote sobre o escudo. Naquele momento, até o barbeiro, o proprietário anterior da baciaescudo, se vê "obrigado" a aceitar a ideia e associar outros objetos ao subuniverso conferido como real por Dom Quixote.

De acordo com esses exemplos, nota-se que os esquemas díspares de interpretação fazem parte do cotidiano dos atores sociais. No entanto, essa disparidade não confere às experiências de realidade um caráter unicamente válido, verdadeiro em uma. Assim, é possível compreender o problema da realidade como a existência de múltiplas realidades. E, nesse sentido, o que se estabelece são relações intersubjetivas em diálogo entre diferentes subuniversos possíveis. Cada realidade tem uma forma de significados particulares e uma maneira única de "relação da consciência com o mundo que permanecerá até que uma experiência de choque - o acordar, o fim do filme, o levantar da cortina - proporcione a transição de um domínio da experiência para outro.” (CORREIA, 2002, p. 10). Ademais,

[...] a consciência de um agente lê o universo de uma forma que implica transitar entre estados particulares da realidade, por meio de diferentes atitudes e estados de consciência, indo e regressando para a atitude natural, que se torna a âncora dessas transições. Apesar de a atitude natural ser o ponto de partida e de chegada destas viagens da consciência, e de o mundo da vida quotidiana ser olhado como a província padrão da realidade, há múltiplas realidades, e uma delas é considerada, pelos formadores da sociedade, "a" realidade, ou seja, o mundo da vida quotidiana. (CORREIA, 2002, p.60). 
Destarte, o uso da literatura de Dom Quixote é reflexivo para Schutz elucidar as diferentes perspectivas de construção dos mundos sociais e suas conexões. No item a seguir pretende-se fazer uma associação com a vida do gaúcho campeiro, segmento social presente em determinado território do Rio Grande do Sul, e a sua perspectiva no mundo social que ele considera sendo real.

\section{O GAÚCHO CAMPEIRO}

O gaúcho pode ser entendido como o habitante de um espaço delimitado à zona da Campanha, região do Rio Grande do Sul, que por ser um agente social constrói, a partir de suas vivências, sua cultura (GUTFREIND, 2006). A formação social dessa região está diretamente ligada às formas de ocupação e povoamento que se deram através de vários tratados entre Portugal e Espanha e que demonstram essa alternância de dominação: Tordesilhas (1494), Madrid (1750), Pardo (1761) e Santo Idelfonso (1777).

Assim, se o século XVI foi marcado por um inicial desinteresse dos portugueses, é no século seguinte que as incursões bandeirantes descobrem os "recursos" úteis à atividade econômica desenvolvida no Nordeste brasileiro. O século XVII foi marcado pela única atividade exploratória luso-brasileira de capturar indígenas e gado, culminando com o assolamento das reduções jesuíticas. Esse processo configurou o Rio Grande do Sul como um grande campo de pastagem limitado pelas matas, sendo, por longo período, uma área pastoril, como destaca Nilo Bernardes (1997).

Esse processo culmina com a (trans) formação de um segmento social compreendido como "gaúcho". Sem a preocupação com os limites, esses homens, que administravam o seu tempo de trabalho, eram considerados "vagos" ou "gaudérios". Para Ieda Gutfreind (2006, p. 242), “'gaúcho', assim, no que se refere à sociedade do período colonial, compreende 'peões', 'vagos', 'gaudérios' ou qualquer outra denominação que represente o homem da Campanha". A presença de tais indivíduos contribuiu para essa miscigenação e para a designação do termo "gaúcho".

No entanto, a cobiça da Coroa portuguesa pelos campos de pastagem, foi decisiva para o povoamento do território sul-rio-grandense. Segundo Mário Maestri (2006), a partir dos anos de 1730, foram concedidas as primeiras sesmarias. A doação de sesmarias de terras 
visava à manutenção do arrebanhamento de gado e, por consequência, o povoamento e ocupação do território. Com a apropriação do modelo jesuíta de propriedade, concatenado com a doação de terras, ocorre uma amplificação das estâncias na Campanha do Rio Grande do Sul.

A dinâmica histórica do território permanece assentada nesse sistema econômico: a atividade agropastoril. A região sudoeste rio-grandense possui um número efetivo dos rebanhos dentro do Rio Grande do Sul correspondente a 33,91\% para bovinos, 52,91\% para ovinos e 31,60\% para equinos (Instituto Brasileiro de Geografia e Estatística - IBGE, 2006).

O contexto reflete um padrão econômico e institucional na região e na configuração de um tipo de segmento social específico desse contexto: gaúcho campeiro. Assim, o comportamento e o modo de vida "típico" do contexto rural da Campanha do Rio Grande do Sul permaneceram com uma estrutura constante. Práticas, costumes, comportamentos, objetos, etc, seguiram uma constância, pondo em relação o que representa o arcaico e o moderno, talvez pela parca ação deste último no sistema produtivo configurado até os dias atuais na Campanha.

\section{GAÚCHO CAMPEIRO E AS EXPERIÊNCIAS DA REALIDADE}

O primeiro ponto de análise é o contexto de vida do campeiro. Um contexto de mundo rural que, assim como Alonso Quijana, está muito voltada para as experiências no mundo social de forma direta. As interações face a face oriundas de um espaço de copresença são elementos pertinentes na construção dos sentidos.

$\mathrm{Na}$ análise da vida do gaúcho tem-se como baluarte do contexto de vida o trabalho (lida), o campo e o galpão ${ }^{1}$. Ou seja, as relações sociais e de trabalho estão estruturadas a partir dos encontros no tempo-espaço em torno dessa base (MARTINS, 2011). O campo, no sentido prático de espaço com terra e pastagem onde ficam os animais, é o espaço de trabalho. O tempo de trabalho está diretamente ligado a este espaço e as relações sociais também estão muito centradas nos deslocamentos no campo. "Os encontros são mantidos, em sua maioria, com parentes. Os amigos também são visitados, mas nos dias da semana, em virtude dos

1 Sob o olhar regional, o galpão é uma "construção rústica edificada na sede da estância, destinada ao abrigo de homens e animais bem como a guarda de materiais e outras serventias. Possui, geralmente, uma área de chão batido e uma outra assoalhada com madeira bruta para guardar ração, arreios, ferramentas e outros utensílios" (BOSSLE, 2003, p. 259). 
deslocamentos na lida campeira e nos encontros no bolicho ${ }^{2}$, para compra de algum suprimento" (MARTINS, 2011, p. 72). O trabalho está contido, historicamente, por uma prática rústica. Essa atividade, que se efetiva no campo, contém elementos arcaicos com o trato e o manuseio de animais.

Por seu turno, o galpão é um elemento carregado de significado no contexto de vida do gaúcho campeiro. Na região da Campanha, reafirmando o que já foi mencionado, há a peculiaridade da presença das fazendas de criação de animais. De modo geral, na fazenda, há a casa do proprietário e o galpão que, para muitos campeiros, torna-se a 'sua casa'. É desta forma que, se na cidade há a casa para trabalhador urbano, no rural existe o galpão para o trabalhador do campo.

Assim como Roberto DaMatta (1986) fala em casa no sentido de não se associar somente a um local de dormitório, refeitório ou de proteção contra as intempéries climáticas, mas num conjunto de objetos, relações, valores e construções que os grupos adquirem e preservam, deve-se entender o galpão para o campeiro. No galpão das fazendas está contida "uma dimensão da vida social permeada de valores e de 'realidades múltiplas'. Coisas que vêm do passado e objetos que estão presentes, pessoas que estão saindo deste mundo e pessoas que a ele estão chegando”. (DaMATTA, 1986, p.19, grifo nosso).

É neste espaço onde se percebe a maioria das relações sociais na fazenda: entre campeiros; entre campeiros e familiares; e entre campeiros e o proprietário da fazenda (e/ou gerente). E mais: até para o recebimento de algum “estranho" o galpão contém um elemento de aproximação social.

Essas experiências de copresença são ampliadas quando ocorrem deslocamentos no espaço vivido. Especialmente quando a ida em espaços de sociabilidade se amplia no campo: visitas à fazenda vizinha; ida ao bolicho para compra de mantimentos; participação em algum rodeio $^{3}$ ou baile na comunidade. Além disso, o acesso aos serviços urbanos, como os bancários, hospitalares e comerciais, representa uma dinâmica de interação face a face e, consequentemente, de construção da realidade social. No entanto, supor que as experiências da realidade estariam limitadas ao contexto de copresença é uma forma limitada de entender o sentido do mundo social para o gaúcho campeiro. Miguel de Cervantes já denunciava como é possível construir a realidade a partir de dispositivos mediadores: os livros para Dom Quixote.

\footnotetext{
2 "Pequeno estabelecimento comercial; bar, vendinha, bodega, taberninha." (BOSSLE, 2003, p. 86).

3 Festa do meio rural com competição entre grupos de campeiro em atividades de laçar o gado, dentre outras.
} 
Assim, para o gaúcho campeiro também é possível falar em experiências mediadas da realidade. O contexto que se estabelece na vida dos gaúchos pressupõe uma ordenação relacional entre o arcaico e moderno. $\mathrm{O}$ arcaico muito representado pelo parco dinamismo do meio rural que incide, dentre outros, sobre a manutenção da rusticidade da atividade laboral e nas formas de vestir, aparelhos de trabalho e objetos cotidianos (MARTINS, 2011).

Por seu turno, o moderno surge diante da tecnificação das atividades de trabalho, dos recursos auxiliares nas ações cotidianas (máquinas, aparelhos, objetos, etc.) e das novas tecnologias da informação e comunicação (TICs). A apropriação das TICs alteraram as interações no tempo-espaço, ampliando o entendimento de si, do mundo e das relações (THOMPSON, 1998). No que tange aos gaúchos campeiros é possível observar, conforme o quadro abaixo, as seguintes configurações das TICs no seu cotidiano.

\begin{tabular}{|l|l|}
\hline \multicolumn{1}{|c|}{ TICs } & \multicolumn{1}{c|}{ APROPRIAÇÃO } \\
\hline Celular & $\begin{array}{l}\text { - Utilizado antes da energia elétrica; } \\
\text { - Inserido no cotidiano e na indumentária de trabalho; } \\
\\
\text { - Substitui o rádio para a comunicação interpessoal; } \\
\text { - Quebra de isolamento social. }\end{array}$ \\
\hline Rádio & - Atuante na rotina; \\
& - Conteúdo regional; \\
& - Percepção para o desenvolvimento; \\
& - Atua no sentimento de pertencimento. \\
\hline TV & - Consolidação da reflexividade identitária; \\
& - Ampliação da realidade do mundo; \\
& - Conteúdo selecionado ao contexto de vida. \\
\hline
\end{tabular}

Quadro 01: TICS e a apropriação pelos campeiros

Fonte: Martins (2011), com adaptações.

Desta forma, constata-se que a apropriação desses dispositivos, na perspectiva de uma interação mediada, reflete um mecanismo de mediação que contribui diretamente para a construção do 'subuniverso campeiro'. Assim, no subuniverso os dispositivos atuam como mediadores das formas de se constituir como sujeito e comunidade e como mediadores das formas de construir, ordenar e interpretar o mundo e seus significados (THOMPSON, 1998). A experiência em copresença e mediada provoca uma "mistura" entre a ciência/crendice, técnica/misticismo, ou entre arcaico/moderno. Isso constituiu o conhecimento de senso comum dos gaúchos campeiros (MARTINS, 2011). O conhecimento é organizado como uma colcha de retalhos altamente desigual, na qual experiências claras estão mescladas com vagas conjunturas (SCHUTZ, 1983). É nesse contexto que se pode falar em 'problema da realidade' na vida de gaúcho campeiro. 


\section{O GAÚCHO CAMPEIRO E O 'PROBLEMA DA REALIDADE'}

A premissa que orienta a análise do campeiro com a realidade é a mesma pensada para Dom Quixote: o mundo da cavalaria é o subuniverso de Dom Quixote e é sobre este que ele confere o valor da realidade. Por conseguinte, o mundo rural é o subuniverso dos campeiros e é sobre este que se confere o valor da realidade. O 'problema' da realidade está no entendimento do que é desenvolvimento e de como a região da Campanha está representada para os campeiros. Nesse sentido, procurou-se compreender qual o sentido de desenvolvimento é construído socialmente. Na proposta do estudo três distintos espaços rurais e em torno de dez campeiros foram analisados nesse contexto.

Sugerir 'problema' e não problema decorre da ideia de por em suspensão qualquer construção apriorística sobre a definição. Ou seja, o deslocamento de perspectiva de Schutz (1983) prevê a relativização do conceito a partir da compreensão do mundo social construído pelos indivíduos em análise. Sob outra ótica, a ação social destes agentes deve ser vista como sendo calcada na conexão causalidade e valores sociais, aos moldes do pensamento compreensivo de Max Weber (FREUND, 2010).

Assim, se se considerar os outros - aqueles não pertencentes ao meio rural -, como ‘empíricos neopositivistas', ter-se-á inúmeras visões - causas e valores -, de desenvolvimento e da região como opostas e contraditórias ao pensamento dos gaúchos campeiros. Vale dizer, indicadores econômicos como PIB, renda per capital, índice de Gini, etc. demonstram quantitativamente a ideia de desenvolvimento e a visão da região como "pobre", "subdesenvolvida", "estagnada", etc. No entanto, o subuniverso de vida, articulado com elementos de copresença e mediados, faz com que o gaúcho considere seu espaço desenvolvido, rico, sem pobreza. Para eles 'quem produz bastante é desenvolvido' e isso está na base do seu subuniverso rural. A noção de desenvolvimento é diretamente associada à atividade realizada e ao espaço habitado.

O sentido de desenvolvimento está inserido no ambiente rural da produção agropecuária. O vínculo com a categoria "espaço" também é evidente. Por exemplo, quanto maior o espaço, maiores as condições de engordar os animais e, consequentemente, maior produtividade de carne. (MARTINS, 2011, p. 60). 
Isso resulta da cognição do termo desenvolvimento estar voltado ao de produtividade. Se o tempo e o espaço são vividos e utilizados na busca de uma maior produtividade, então a Campanha do Rio Grande do Sul é considerada desenvolvida pelos gaúchos campeiros.

Mas a causa dessa diferenciada construção da realidade não está somente sobre a base material, e em grande medida objetiva, da existência. Novamente é preciso recorrer à influência de Weber na fenomenologia para entender que é “a interpretação fundamentada na relação com os valores que lhe confere uma significação, por se colocarem em evidência ao mesmo tempo os motivos e o fim de uma atividade." (FREUND, 2010, p. 45).

Ora, entender o desenvolvimento como produtividade e a região como desenvolvida passa obrigatoriamente pela relação desses indivíduos com o espaço e com as interações. $\mathrm{O}$ valor que subjaz é o de pertencimento ao território. Construído pelo trabalho (base material), pelas interações no cotidiano e pelas interações mediadas que reafirmam os sentimentos de orgulho, reflexividade positiva sobre o que se faz e o que se é (MARTINS, 2011).

Para os gaúchos campeiros, o espaço da Campanha se torna um território de orgulho e pertencimento porque eles entendem que fazem parte e dão sustentação a essa condição. Ou seja, se a região se "sustenta", muito se deve ao desempenho desses atores sociais. Além disso, essa situação é dinamizada pela mídia e novamente a relação do conteúdo midiático com o campeiro é central para essa reflexividade do pertencimento deste indivíduo em relação ao território. Se eu estou "refletido" na mídia, com orgulho por pertencer a um território, como poderia pensá-lo como não desenvolvido se eu faço parte dessa história, desse orgulho? Essa indagação é sugerida na medida em que se relaciona o espaço, a cultura do gaúcho e o conteúdo midiático que ele assimila e reflete (MARTINS, 2011, p. 84).

Em termos fenomenológicos está presente a noção de comunidade em relação à construção do pertencimento e a "evidente" noção de desenvolvido. O que para o "olhar" de outro grupo pode ser estranho e até nulo em termos de compreensão da realidade. Essa diferença de olhar está no âmbito dos significados finitos da comunidade dos gaúchos campeiros. Como sugere Correia (2002, p. 15), mencionando o pensamento de Schutz,

[...] o facto de as comunidades (ou sejam, os grupos sociais e culturais que são a expressão concreta do mundo da vida) serem sempre olhadas como estranhas pelos outros que lhe são próximos e implicarem, por sua vez, uma estranheza em relação a esses mesmos próximos, faz com que o mundo da vida perca a sua evidência. Na verdade, a evidência existe e Schutz não a nega. Porém é completamente limitada, só é evidente para os que a consideram enquanto tal e como tal. Cada realidade - e elas são múltiplas como o autor nunca se esquecerá de lembrar - é também um âmbito de significado finito e, consequentemente, os significados só são partilháveis no interior de cada uma. 
Assim, é possível inferir que a relação com o espaço, os mecanismos de interação social, ora em copresença enquanto comunidade, ora por dispositivos midiáticos, produz aquilo que Correia (2002) associa à consciência da contingência de cada mundo da vida. Ou seja, a existência das múltiplas realidades e, consequente, visão relativamente natural do mundo própria de cada comunidade.

\section{7 À GUISA DA CONCLUSÃO}

Como sugere Schutz (1983), na leitura da realidade construída por Dom Quixote, existem variações cuidadosamente elaboradas para compreender e experimentar a realidade. Essas variações são construídas através de diferentes elementos que ultrapassam a objetividade e a materialidade da vida. Dom Quixote apresenta o contexto de vida, as interações em copresença e as interações mediadas. A partir disso, confere sentido para objetos, pessoas e, até mesmo, vocábulos.

Se para o mundo da cavalaria de Dom Quixote havia o meio rural, as interações com as pessoas e objetos e a leitura dos livros, para o gaúcho campeiro também existem elementos pertinentes à constituição do seu mundo: meio rural; interação com pessoas e objetos; e uma amplificada interação mediada por meios das tecnologias da comunicação e informação.

$\mathrm{Na}$ vida do gaúcho campeiro esses argumentos misturam-se na base material da vida e nas relações cognoscíveis. Ou seja, dentro da própria atividade laboral, do sistema que ela faz parte e, também, dentro do que pode ser conhecido e experimentado nos processos de interação.

A realidade do desenvolvimento para o campeiro sugeriu um viés econômico (produtividade) e sociológico (pertencimento), oriundos de um universo específico. O gaúcho campeiro é um exemplo de que é preciso ampliar a compreensão dos diferentes universos construídos pelos atores sociais, pois só conhecendo as diversas perspectivas de realidade será possível reduzir os paradoxos e contradições constitutivos do mundo.

\section{REFERÊNCIAS}

BERGER, Peter; LUCKMANN, Thomas. A construção social da realidade. 13 ed. Petrópolis: Vozes, 1996. 247p. 
BERNARDES, Nilo. Bases geográficas do povoamento do Rio Grande do Sul. Ijuí: Editora da Unijuí, 1997.135p.

BOSSLE, João Batista Alves. Dicionário gaúcho brasileiro. Porto Alegre: Artes e Ofícios, 2003. 541p.

BRIGGS, Asa; BURKE, Peter. Uma história social da mídia: de Gutenberg à internet. 2 ed. Rio de Janeiro: Jorge Zahar, 2006. 375p.

CAPALBO, Creusa. Metodologia das ciências sociais: a fenomenologia de Alfred Schutz. Rio de Janeiro: Antares, 1979. 102p.

CERVANTES, Miguel de. Dom Quixote de la Mancha. São Paulo: Abril Cultural, 1978. $609 \mathrm{p}$.

CORREIA, João Carlos. A teoria da comunicação de Alfred Schutz. Covilhã: UBI, 2002. 273p. Disponível em:

$<<$ http://ubi.academia.edu/JoaoCarlosCorreia/Books/358423/A_Teoria_da_Comunicacao_de_ Alfred_Schutz >>. Acesso em: 21 de julho de 2012.

DaMATTA, Roberto. O que faz o Brasil, Brasil? Rio de Janeiro: Rocco, 1986. 126p.

FREUND, Julien. Sociologia de Max Weber. Rio de Janeiro: Forense Universitária, 2010. 208p.

GIDDENS, Anthony. Sociologia. 6 ed. Porto Alegre: Artmed, 2005. 600p.

GUTFREIND, Ieda. O gaúcho e sua cultura. In: BOEIRA, Nélson; GOLIN, Tau (coord.). História Geral do Rio Grande do Sul. Vol. 01. Passo Fundo: Méritos, 2006. 241-254p.

Instituto Brasileiro de Geografia e Estatística - IBGE. Sistema IBGE de Recuperação Automática: SIDRA, 2006. Disponível em http://www.sidra.ibge.gov.br/

MAESTRI, Mário. Uma breve história do Rio Grande do Sul: da pré-história aos dias atuais. Vol. 01. Passo Fundo: UPF Editora, 2006. 157p.

MARTINS, Tiago Costa. Vida de gaúcho campeiro: cultural regional, mídia e desenvolvimento. Jundiaí: Paco Editorial, 2011. 124p.

SCHÜTZ, Alfred. Dom Quixote e o problema da realidade. In: LIMA, Luiz Costa. Teoria da literatura em suas fontes. 2 Ed. Rio de Janeiro: F. Alves, 1983. 191-213p.

THOMPSON, John B. A mídia e a modernidade: uma teoria social da mídia. 8 ed. Petrópolis: Vozes, 1998. 261p. 
Marcela Guimarães Silva

Professora Adjunta II do curso de Relações Públicas - ênfase em produção cultural; coordenadora da Especialização em Atividades Criativas e Culturais e coodenadora do Observatório Missioneiro em Atividades Criativas e Culturais (OMiCult) na Unipampa.

Tiago Costa Martins

Professor Adjunto I do curso de Relações Públicas - ênfase em produção cultural; coodenador do Observatório Missioneiro em Atividades Criativas e Culturais (OMiCult) na Unipampa. É pós-doutorando em Administração pela Universidade de Fortaleza (Unifor).

Esta obra está licenciada sob uma Licença Creative Commons. 